\title{
A Comprehensive Perspective of Waste Heat Recovery Potential from Solar Stirling Engines
}

\author{
Siddharth Ramachandran*, Naveen Kumar, and Venkata Timmaraju Mallina \\ Indian Institute of Information Technology, Design and Manufacturing (IIITDM), Kancheepuram \\ Chennai, India-600127
}

\begin{abstract}
Despite the higher efficiency advantage, the cost reduction of PV technology has been more successful compared to the dish Stirling engine (DSE) due to the large market volume and sturdy competition. Irrespective of the types of source, there exists a potential of waste heat recovery from Stirling engines operating at higher temperature regime. Accordingly, to make DSE commercially viable and efficient, innovative ways such as hybridization (combing a bottoming cycle), Co-generation, Tri-generation etc. need to be explored. In this paper, the techno-economic feasibility of hybridization of a typical solar DSE with a bottoming organic Rankine cycle (ORC) via. a heat recovery vapour generator (HRVG) is explored. The overall energetic and exergetic efficiency of the DSE has been improved by $5.79 \%$ and $5.64 \%$ while recovering the waste heat through a bottoming ORC. The design and effective incorporation of the HRVG with cooler side of the Stirling engine is identified to be crucial for the overall exergetic performance of solar Stirling-ORC. Further, the economic feasibility of a solar String-ORC combination is evaluated in terms of levelized cost of electricity (LCOE) and payback period. Both LCOE and payback period are found to be in comparable range with the PV technology.
\end{abstract}

\section{Introduction}

Renewable energy sources play a vital role in framing policies related to energy security, economic development, environmental protection (3E's) etc. worldwide [1]. Effective and extensive utilization of renewable (solar/wind) energy is one of the most sought-after solutions to achieve the goal of self-sustainable world. Concentrated sunlight is found to be useful for high temperature applications like power production [2], industrial process heating [3] etc. Stirling engine mounted on a parabolic dish concentrator is a stateof-the-art technology by which domestic $(1-5 \mathrm{~kW})$ and industrial $(10-25 \mathrm{~kW})$ level electricity can be generated from solar energy. Solar-to-electric conversion of such a device has been recorded to be $29.4 \%$ in 1984 (highest recorded solar energy conversion efficiency) [4] and since then there has been an interest in the potential of these systems for reliable renewable power generation. However, in terms of economic viability, parabolic dish concentrated Stirling engines (DSE) are often directly compared with the photovoltaic (PV) technology.

\footnotetext{
${ }^{*}$ Corresponding author: mdm16d001@iiitdm.ac.in
} 
Despite the higher efficiency advantage, the cost reduction of PV technology has been more successful compared to the DSE due to the large market volume and sturdy competition. The major reason for this is the flexibility to store the energy produced/utilized. Even though, thermal energy storage (TES) systems are much cheaper compared to the electric battery, coupling of TES system with DSE suffers significant technical challenges and sizing issues. Often, Stirling engines are explored as an excellent waste heat recovery device and very few literatures focus on the recovery of waste heat from these devices [5][8]. Nevertheless, irrespective of the type of source, there is always a potential of waste heat recovery from Stirling engines operating in higher temperature regime (above $650^{\circ} \mathrm{C}$ ) [3], [9], [10]. Thus, in order to make DSE commercially viable and efficient, innovative ways such as hybridization (combing a bottoming cycle), Co-generation (power and heating), Tri-generation (power, heating and cooling) etc. must be adapted.

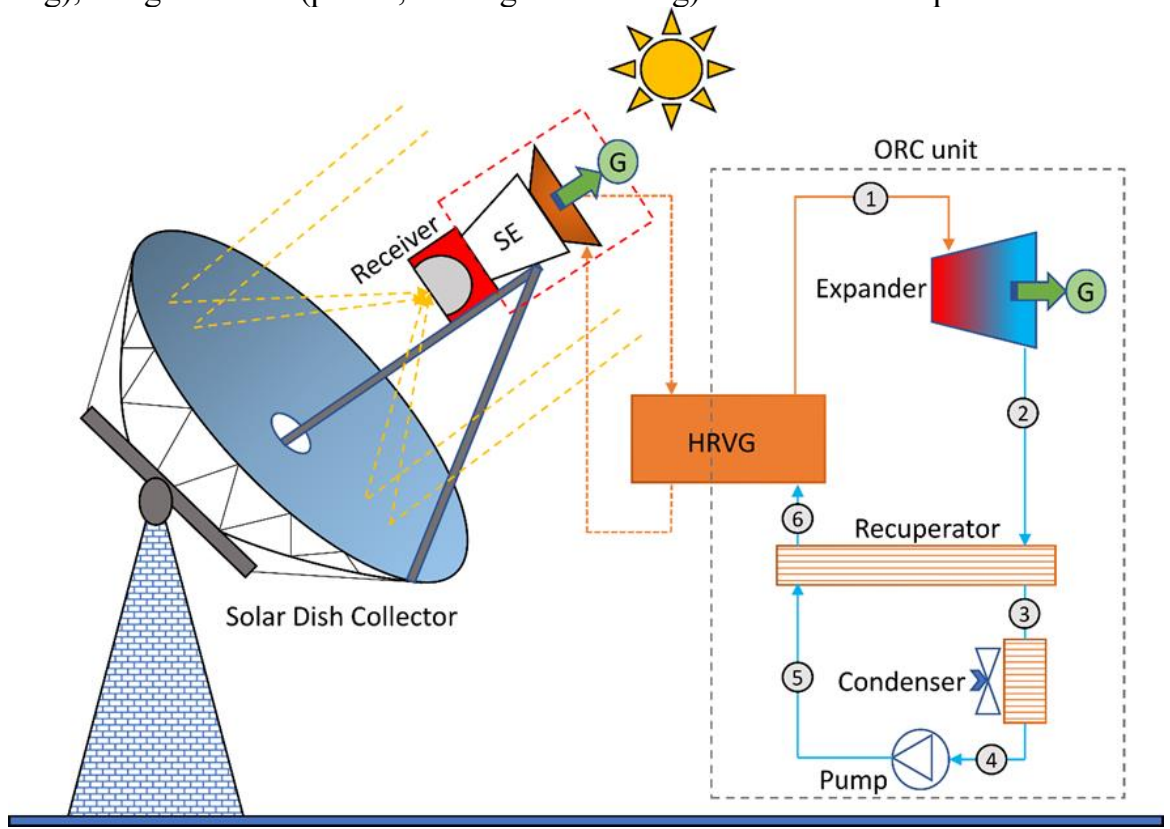

Fig. 1. Component diagram of proposed combined Solar Stirling-ORC

In this paper, the techno-economic feasibility of hybridization of a typical solar DSE with a bottoming organic Rankine cycle (ORC) via. a heat recovery vapour generator (HRVG) is explored (see figure 1). The proposed model involves detailed quantification of heat transfer losses from parabolic dish concentrator, receiver, Stirling engine and ORC for realistic performance prediction of the combined cycle. The finite time thermodynamic approach has been employed to determine the maximum output power and corresponding thermal efficiency of the DSE under different working fluid temperature limits. Waste heat lost from DSE has been utilized for producing additional work through ORC. The proposed model of solar Stirling-ORC has been applied to quantify the component wise (dish concentrator, receiver, HRVG, ORC unit etc.) performance and computed the energetic as well as exergetic feasibility of the combination. Further, the economic feasibility of a solar Stirling-ORC combination is evaluated in terms of levelized cost of electricity (LCOE) as well as payback period in Indian climatic and economic context. 


\section{Thermodynamic Model}

The major components of the proposed combined Stirling-ORC are a parabolic solar dish collector with two-axis tracking, cylindrical cavity receiver, Stirling engine with cooling loop connected to a heat recovery vapour generator (HRVG), which is connected to typical recuperative ORC unit consisting of expander, condenser, recuperator and pump (as depicted in figure 1).

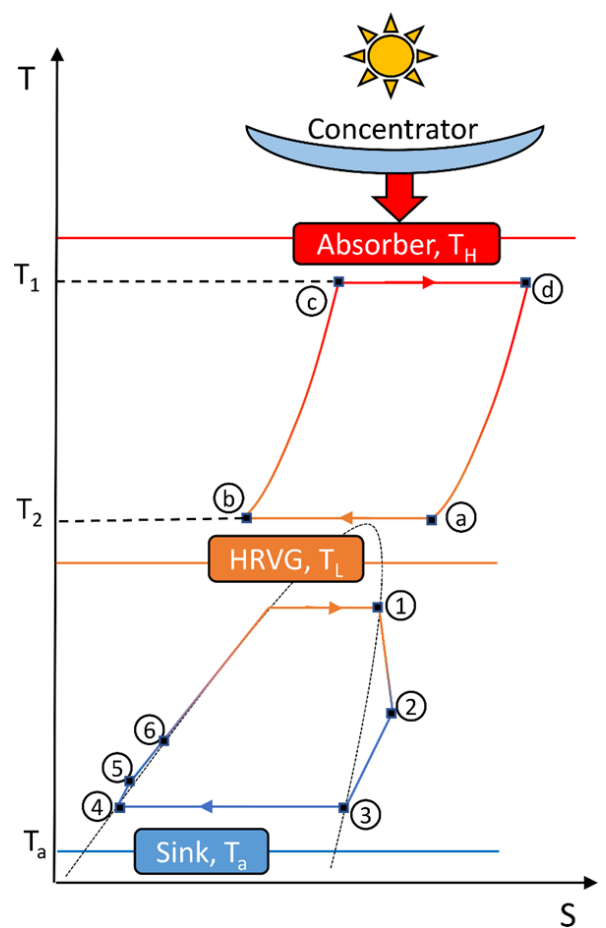

Fig. 2. T-S representation of solar Stirling-ORC

The schematic, shown in Fig. 2, illustrates the operation of a combined solar S-ORC system depicting the combination of Stirling cycle consisting of two isothermal and two isochoric processes and ORC, with two isobaric processes and isentropic processes on a temperatureentropy diagram. The irreversible Stirling heat engine is operating between a heat source with finite heat capacity (Absorber) and a HRVG. The waste heat recovered from the Stirling cycle by the HRVG is used to evaporate the working fluid of a bottoming ORC.

\subsection{Losses associated with solar parabolic dish collector-receiver system}

The performance of the solar S-ORC depends on the net heat input to the DSE, which in turn is governed by the design and orientation of solar dish collector and receiver system. Thus, the design and modelling of collector and receiver becomes a vital part in the overall performance of solar S-ORC. A geometric-optical model [4] is considered for predicting the performance of collector system and a detailed heat transfer model [9], [11] is employed for simulating the real-time performance of a cylindrical cavity-type receiver. The fraction of heat transferred to the Stirling engine have been estimated by accounting the various thermal losses from the receiver. 


\subsection{Output power and thermal efficiency of Stirling heat engine}

The finite time thermodynamic approach has been employed to determine the maximum output power and corresponding thermal efficiency of the DSE under different working fluid temperature limits. The power output and thermal efficiency of the Stirling heat engine is given as [7], [12], [13],

$$
\begin{gathered}
P_{s}=\frac{Q_{H}-Q_{L}}{\tau}=\frac{\left(T_{1}-T_{2}\right)}{\frac{T_{1}+A_{1}\left(T_{1}-T_{2}\right)}{\left\{h_{H C}\left(T_{H}-T_{1}\right)+h_{H R}\left(T_{H}^{4}-T_{1}^{4}\right)\right\}}+\frac{T_{2}+A_{1}\left(T_{1}-T_{2}\right)}{h_{L C}\left(T_{2}-T_{L}\right)}+F_{1}\left(T_{1}-T_{2}\right)} \\
\eta_{s}=\frac{Q_{H}-Q_{L}}{Q_{H}}=\frac{\left(T_{1}-T_{2}\right)}{T_{1}+A_{1}\left(T_{1}-T_{2}\right)+k_{0}\left(T_{H}-T_{L}\right)\left\{\frac{T_{1}+A_{1}\left(T_{1}-T_{2}\right)}{\left\{h_{H C}\left(T_{H}-T_{1}\right)+h_{H R}\left(T_{H}^{4}-T_{1}^{4}\right)\right\}}+\frac{T_{2}+A_{1}\left(T_{1}-T_{2}\right)}{h_{L C}\left(T_{2}-T_{L}\right)}+F_{1}\left(T_{1}-T_{2}\right)\right\}}
\end{gathered}
$$

where $F_{1}=2 \tau_{R} / n R \ln \left(r_{v}\right)$ and $A_{1}=C_{v}\left(1-\varepsilon_{r}\right) / R \ln \left(r_{v}\right)$. In order to maximize the variation in output power with respect to temperature, the output power is differentiated with respect to the working fluid at temperature at hot end, $d P_{s} / d T_{1}=0$ to find its optimal. From table 1 , it can be seen that the predicted performance of the Stirling engine followed in the present investigation is in line with the existing literature, thus validating the FTT approach adopted in the manuscript.

Table 1: Validation of the FTT approach in the present investigation.

\begin{tabular}{|l|lllllll|}
\hline \multicolumn{4}{|c}{} & \multicolumn{3}{c|}{ (Temperature in $\mathrm{K})$} & \multicolumn{2}{c|}{ Objectives } \\
\hline Literature & Type & $\mathrm{T}_{1}$ & $\mathrm{~T}_{2}$ & $\mathrm{~T}_{\mathrm{H}}$ & $P_{s}(\mathrm{~W})$ & $\eta_{s}(\%)$ \\
\hline Ahmadi et. al [14] & Theoretical & 884 & 442 & 1100 & 10640.8 & 29.05 \\
Yaqi [13] & Theoretical & 923.9 & 462 & 1100 & 10164.2 & 30.81 \\
Present work & Theoretical & 926.9 & 463 & 1100 & 10159.7 & 28.91 \\
Reinalter et. al [15] & Experiment & 913 & - & 1123 & 12350 & 22.5 \\
\hline
\end{tabular}

\subsection{Waste heat recovery organic Rankine cycle}

Now the heat lost from the Stirling engine to HRVG has to be recovered by a bottoming ORC. For this, an intermediate external fluid which carries the heat from the cold end of Stirling engine to HRVG can be exploited. Previous literature in this genre assumes that the temperature at which heat is rejected from the Stirling cycle is equal to that of the temperature gained by the ORC [8], [14]. However, heat transfer from Stirling engine working fluid, at cold end, to evaporator of the ORC requires a complex heat exchanger and also needs ORC to be mounted with the Stirling engine on the parabolic dish, which seems to be difficult and impractical proposition to implement. Thus, considering the issues related with operability of the above-mentioned design, there will be some heat losses during this heat transfer from Stirling engine to ORC and these have been accommodated in the present analysis by introducing effectiveness of HRVG and a pinch point temperature difference.

$$
Q_{\text {in }}=\varepsilon_{\text {hrvg }} \times Q_{L}
$$




$$
T_{[1]}=T_{L}-\Delta T_{\text {Pinch }}
$$

where $\varepsilon_{h r v g}$ is the effectiveness of the HRVG which has a practical range of 0.5 to 0.7 [16] and $\Delta T_{\text {Pinch }}$ is the pinch point temperature difference between the HRVG working fluid and ORC working fluid at evaporator.

Table 2: Component-wise energy and exergy balance equations of the ORC system [16]

\begin{tabular}{|c|c|c|}
\hline Component & Energy balance & Exergy balance \\
\hline Evaporator & $\begin{array}{c}Q_{i n}=m_{O R C}\left(h_{1}-h_{6}\right) \\
T_{e}=T_{[1]}\end{array}$ & $\begin{array}{c}\pi_{e}=E x_{e}-m_{O R C}\left(e x_{1}-e x_{6}\right) \\
E x_{e}=Q_{i n}\left(1-\frac{T_{0}}{T_{e}}\right)\end{array}$ \\
\hline Turbine & $\begin{array}{c}h_{2}=h_{1}-\eta_{S, \exp }\left(h_{1}-h_{2, S}\right) \\
W_{T}=m_{O R C}\left(h_{1}-h_{2}\right)\end{array}$ & $\begin{array}{c}\pi_{T}=m_{O R C}\left(e x_{1}-e x_{2}\right)-E x_{T} \\
E x_{T}=W_{T}\end{array}$ \\
\hline Recuperator & $\varepsilon_{\text {rec }}=\frac{h_{6}-h_{5}}{h_{2}-h_{3}}$ & $\pi_{r e c}=m_{O R C}\left(e x_{2}-e x_{3}\right)-m_{O R C}\left(e x_{6}-e x_{5}\right)$ \\
\hline Condenser & $\begin{array}{c}Q_{\text {out }}=m_{\text {ORC }}\left(h_{3}-h_{4}\right) ; \\
T_{c}=T_{\text {cond }}\end{array}$ & $\begin{array}{c}\pi_{c}=m_{O R C}\left(e x_{3}-e x_{4}\right)-E x_{c} \\
E x_{c}=Q_{o u t}\left(1-\frac{T_{0}}{T_{c}}\right)\end{array}$ \\
\hline Pump & $\begin{array}{c}h_{5}=h_{4}-\frac{1}{\eta_{S, p u m p}}\left(h_{5, S}-h_{4}\right) \\
W_{P}=m_{O R C}\left(h_{5}-h_{4}\right)\end{array}$ & $\begin{array}{c}\pi_{T}=E x_{T}-m_{O R C}\left(e x_{5}-e x_{4}\right) \\
E x_{p}=W_{p}\end{array}$ \\
\hline
\end{tabular}

Thus, the overall maximum power, energy and exergy efficiencies of Solar Stirling-ORC can be expressed as [7], [8],

$$
\begin{gathered}
P_{S-O R C}=P_{m s}+P_{\text {ORC }} \\
\eta_{S-O R C}=\eta_{m s}+\eta_{O R C}-\eta_{m s} \eta_{O R C} \\
\eta_{\text {Overall }}=\eta_{\text {solar }} \eta_{S-O R C}=\frac{P_{S-O R C}}{Q_{\text {sun }}} \\
\eta_{\text {ex }, \text { overall }}=\eta_{\text {ex }, \text { solar }} \eta_{\text {ex }, S-O R C}=\frac{P_{S-O R C}}{E x_{1}}
\end{gathered}
$$

\subsubsection{Economic viability}

Considering the hyper sensitivity of any solar device on its location, data from 6 different locations in India has been evaluated for determining the economic feasibility. Once the annual electricity generation of a specific location is estimated, the economic feasibility of the solar S-ORC can be quantified in terms of unit cost ( $U C$ ) of electric energy generation $(\mathrm{kWh}) /$ levelized cost of electricity (LCOE) and it can be expressed as [3], [17],

$$
U C=\frac{C R F \times C_{I N}+C_{O M}+C_{F}}{E_{N E T}}
$$




$$
C R F=\left[\frac{i(1+i)^{N}}{(1+i)^{N}-1}\right]
$$

where $C R F$ is the uniform series capital recovery factor, $C_{I N}$ is the total installation cost, $C_{O M}$ is the operation and maintenance cost, $C_{F}$ is the fuel cost, $i$ is the interest rate, $N$ is the life span of the device. For the present investigation, taxes, insurance, inflation rate and incentives are not taken into account. These costs have been considered according to the System Advisor Model (SAM), 2014 edition [18]. In order to compare the procuring price for electricity, generated by solar/renewable technology with that of offered by the government of India and to aid in Indian energy policy making, the dollar value is converted into Indian rupees $(1 \mathrm{USD}=73 \mathrm{INR}$ as of 05 February 2021) and major economic indicator, the simple payback period of the solar Stirling-ORC was also calculated by taking the ratio of initial investment and annual cash inflow.

\section{Results and discussion}

While designing energy system, it is always important to identify and quantify the energy and exergy losses from each constituent components. A comparative set of pie charts between a typical parabolic dish Stirling engine and solar S-ORC on the basis of energetic and exergetic power loss is illustrated in figure 6. It can be seen that majority of the energy loss and exergy loss are taking place in Stirling engine and collector, respectively. Previous investigations reveal that apart from the irretrievable irreversible losses from the Stirling engine, approximately, $51 \%$ of heat is lost as waste heat [8], [14], [19]-[22] and this indicates the possibility of integrating a waste heat recovery device into it.
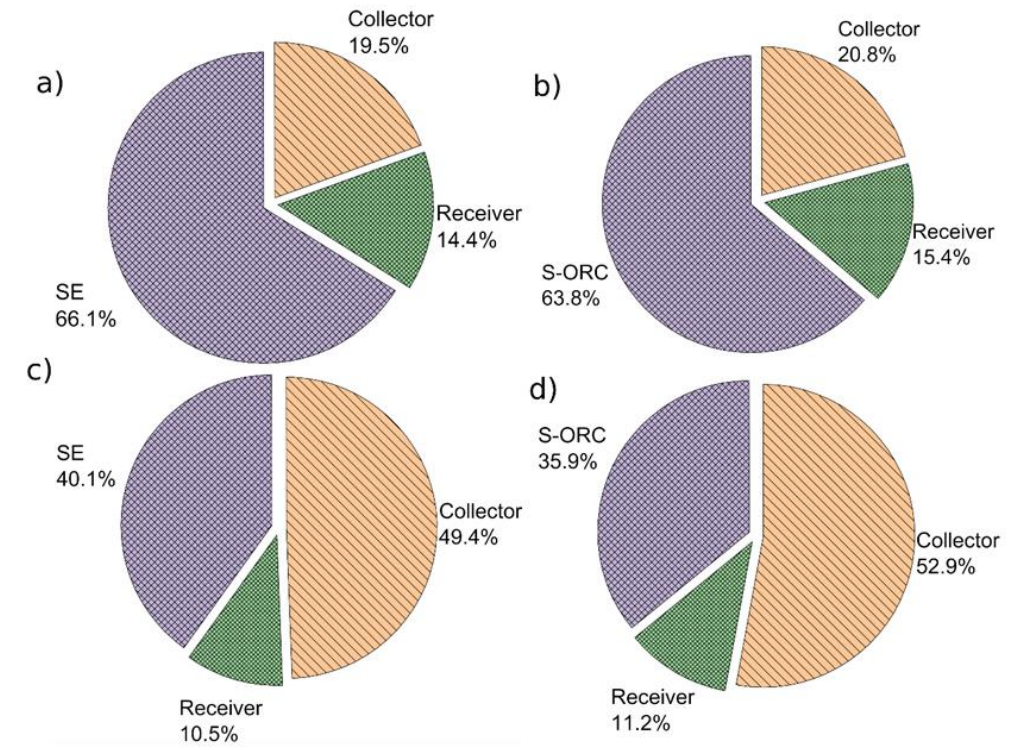

Fig. 3. Component-wise (a, b) energetic and (c, d) exergetic power loss for the parabolic dish concentrating Stirling engine and Stirling-ORC, respectively. 


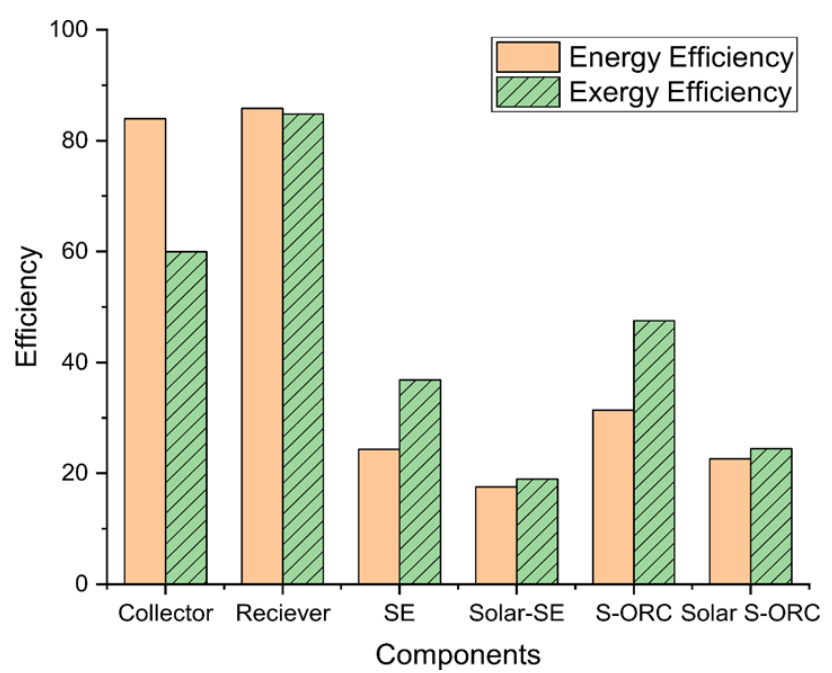

Fig. 4. System level energetic and exergetic efficiency for the parabolic dish concentrating Stirling engine and Stirling-ORC, respectively.

By coupling with a bottoming ORC, through equations (3) and (4), the percentage of energetic and exergetic power loss from the solar parabolic dish Stirling engine can be reduced by $2.3 \%$ and $4.2 \%$, respectively. Exergetically, the percentage of losses are more on solar collector side, indicating the potential scope for improvement in the collector design. A $5.8 \%$ of improvement in overall energy efficiency of the system can be achieved by coupling a bottoming ORC for waste heat recovery from Stirling engine. Also, by integrating with bottoming ORC, a 5.64\% of improvement in overall exergetic efficiency can be achieved (see figure 4).

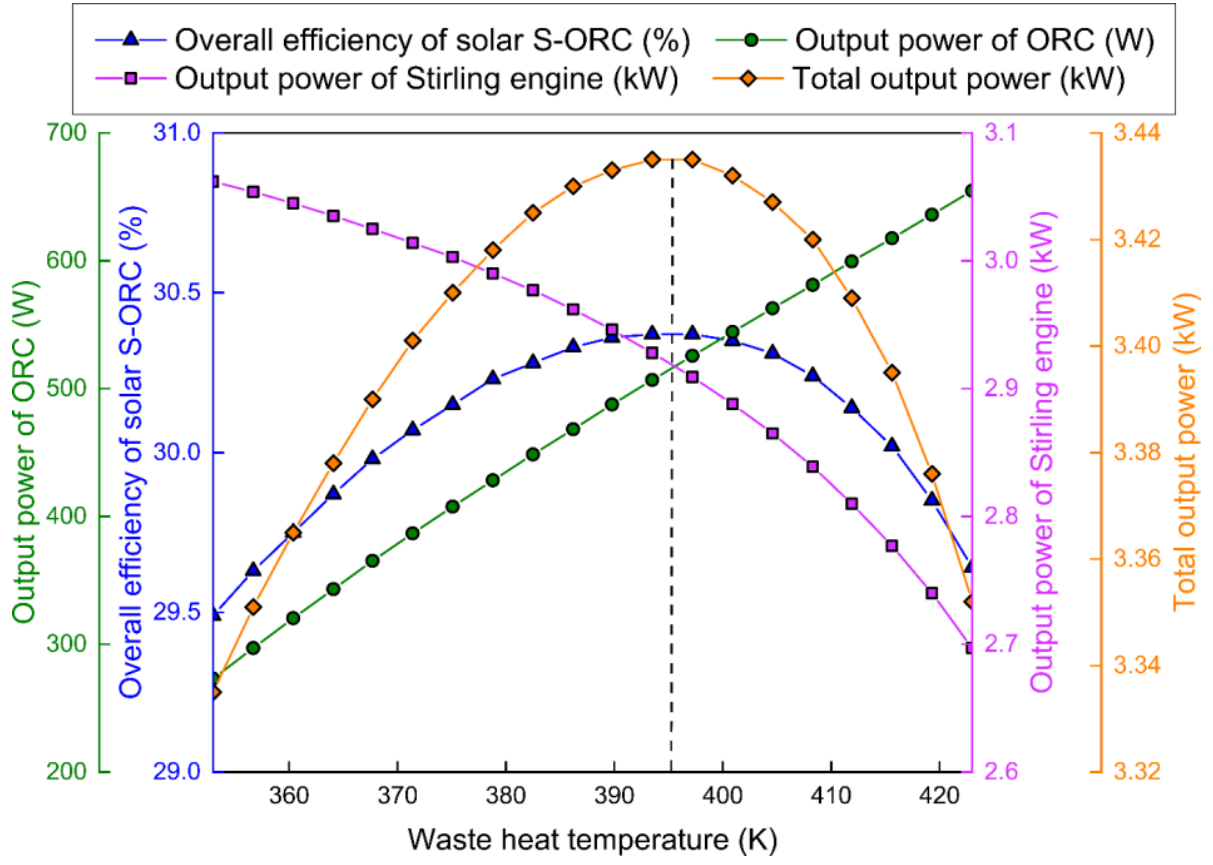

Fig. 5. Effect of waste heat temperature on performance of solar Stirling-ORC 


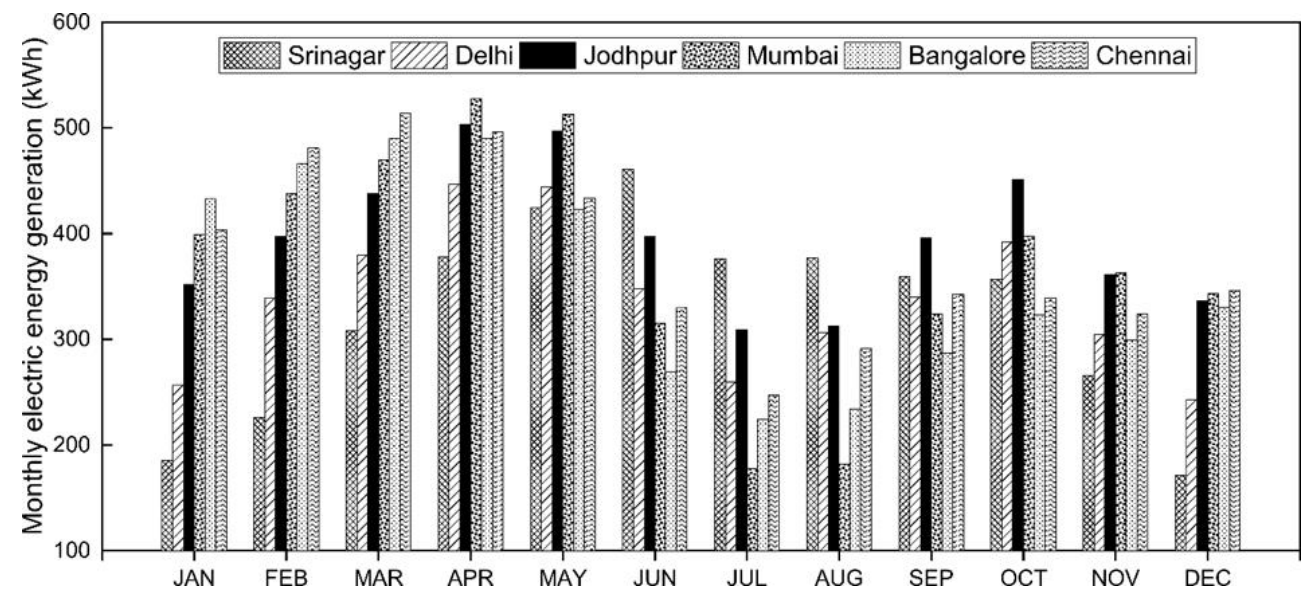

Fig. 6. Monthly average electric energy generation by solar Stirling-ORC for different locations in India.

It can be observed from figure 5, that increase in waste heat temperature, results in decrease in the Stirling engine output power and an increase in ORC output power. Since the HRVG acts as a sink to the Stirling cycle, any increase in sinks temperature reduces cyclic performance, while it is opposite for ORC. Under the given operating conditions, the Stirling output power and ORC output power follow a quadratic and linear dependency on waste heat temperature, respectively. These two conflicting dependencies evolve a dome shaped curve for overall output power indicating the presence of an optimal waste heat temperature $(\sim 395 \mathrm{~K})$ for obtaining maximum overall thermal performance, which can be considered as an optimal design point at which maximum performance of the combined solar Stirling-ORC can be achieved.

In order to evaluate performance any solar energy conversion system economically, it is essential to compute the annual solar irradiance received at a location over a period of time, energy savings, payback period etc. To determine the financial viability of the proposed system relevant calculations have been performed by taking the solar energy data for six different locations in India such as, Srinagar, Delhi, Jodhpur, Mumbai, Bangalore and Chennai. However, the average monthly electricity generation capacity of a solar Stirling-ORC is sensitive to the irradiation received and ambient temperature at a particular region. Figure 6 gives a comprehensive view of monthly electric energy generated by solar Stirling ORC and its variation throughout the year for the different locations, as mentioned earlier, in India. The proposed solar Stirling-ORC do have the capacity to satisfy the monthly energy demand of a typical household $(100-300 \mathrm{kWh})$ at most of the locations considered, especially jodhpur but the proposed system can satisfy the energy demand during day time only. Further, the economic feasibility of solar Stirling-ORC while connected to grid needs to be evaluated. Accordingly, unit cost of electric energy generation or levelized cost of electricity produced by the solar Stirling-ORC and being supplied to the grid has been calculated.

To compare levelized unit electric energy generation (LCOE) as well as to aid the national energy policy making, from a decentralised solar parabolic dish Stirling engine, solar Stirling-ORC and a $50 \mathrm{MW}$ centralised solar parabolic dish Stirling engine power plant [17], has been computed for different interest rates and given in figure 7. The LCOE is found to be lesser for combined solar Stirling-ORC in comparison to solar Stirling engine, signifying the economic feasibility. According to the Jawaharlal Nehru national solar mission, INR 14 is the cost at which government of India will buy each unit of electricity generated by solar power [17]. Considering this as a reference point, 
decentralised solar Stirling- ORC is profitable up to $12 \%$ of interest rate, while for solar Stirling engine it is only up to $10 \%$ over 25 -years life span. However, the unit cost of electric energy generation can be reduced significantly by operating the proposed system as centralised power plant units, which is more profitable.

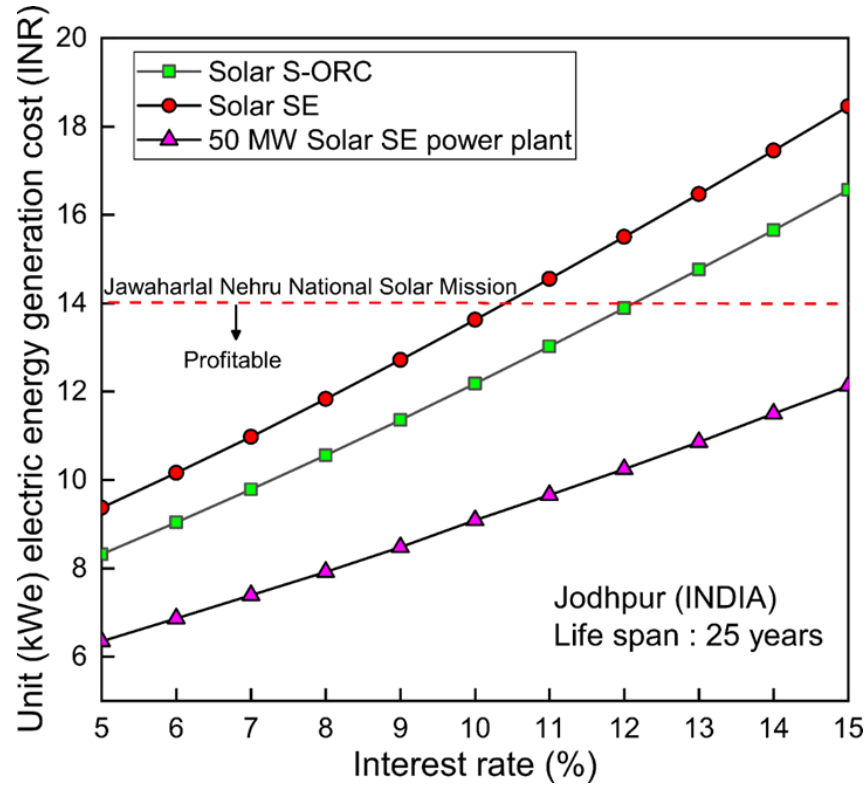

Fig. 7. Unit electric energy generation cost (LCOE) in INR for different interest rates at Jodhpur While considering a coupled $3 \mathrm{~kW}$ solar Stirling engine and ORC system with 25 -year life span and unit electric energy generation cost of 12.4 INR at an interest rate of $10 \%$ can produce around $\sim 7560 \mathrm{kWh} /$ year with a payback period of 5.4 years. Therefore, the economic performance of solar Stirling-ORC system is comparable with a typical $3 \mathrm{~kW}$ solar photovoltaic system which have a typical payback period of $\sim 4$ years.

\section{Conclusion}

In this paper, the techno-economic feasibility of combination of a typical solar DSE with a bottoming organic Rankine cycle (ORC) via. a heat recovery vapour generator (HRVG) is explored and it was found that,

- the overall energetic and exergetic efficiency of the DSE has been improved by $5.79 \%$ and $5.64 \%$ while recovering the waste heat through a bottoming ORC.

- the optimal waste heat temperature for the input variables considered for the present investigation was found to be $\sim 395 \mathrm{~K}$.

- the economic feasibility of a solar String-ORC combination is evaluated in terms of levelized cost of electricity (LCOE) and payback period.

- a typical $3 \mathrm{~kW}$ solar Stirling engine coupled with an ORC system with 25-year life span and unit electric energy generation cost of 12.4 INR at an interest rate of $10 \%$ can produce around $\sim 7560 \mathrm{kWh} /$ year with a payback period of 5.4 years.

Additionally, the proposed system would also contribute to energy saving by producing hot water, if utilized as a CHP unit, which has not been included in the above analysis. 


\section{References}

[1] K. Wang, S. R. Sanders, S. Dubey, F. H. Choo, and F. Duan, "Stirling cycle engines for recovering low and moderate temperature heat: A review," Renew. Sustain. Energy Rev., vol. 62, pp. 89-108, 2016, doi: 10.1016/j.rser.2016.04.031.

[2] B. Kongtragool and S. Wongwises, "A review of solar-powered Stirling engines and low temperature differential Stirling engines," Renew. Sustain. Energy Rev., vol. 7, no. 2, pp. 131-154, 2003, doi: 10.1016/S1364-0321(02)00053-9.

[3] A. Z. Hafez, A. Soliman, K. A. El-Metwally, and I. M. Ismail, "Solar parabolic dish Stirling engine system design, simulation, and thermal analysis," Energy Convers. Manag., vol. 126, pp. 60-75, 2016, doi: 10.1016/j.enconman.2016.07.067.

[4] P. Fraser and P. S. a Klein, "Stirling Dish System Performance Prediction Model," Mech. Eng., vol. Master of, p. 203, 2008.

[5] G. T. Udeh, S. Michailos, D. Ingham, K. J. Hughes, L. Ma, and M. Pourkashanian, "A techno-enviro-economic assessment of a biomass fuelled micro-CCHP driven by a hybrid Stirling and ORC engine," Energy Convers. Manag., vol. 227, no. July 2020, p. 113601, 2021, doi: 10.1016/j.enconman.2020.113601.

[6] M. Chahartaghi and M. Sheykhi, "Energy, environmental and economic evaluations of a CCHP system driven by Stirling engine with helium and hydrogen as working gases," Energy, vol. 174, pp. 1251-1266, 2019, doi: 10.1016/j.energy.2019.03.012.

[7] S. Ramachandran, N. Kumar, and M. V. Timmaraju, "Thermodynamic Investigation of an Irreversible Combined Stirling-Organic Rankine Cycle for Maximum Power Output Condition," J. Eng. Gas Turbines Power, vol. 143, no. 7, pp. 1-7, 2021, doi: 10.1115/1.4049775.

[8] M. Bahrami, A. A. Hamidi, and S. Porkhial, "Investigation of the effect of organic working fluids on thermodynamic performance of combined cycle stirling-ORC," Int. J. Energy Environ. Eng., vol. 4, no. 1, pp. 1-9, 2013, doi: 10.1186/2251-6832-4-12.

[9] F. Nepveu, A. Ferriere, and F. Bataille, "Thermal model of a dish/Stirling systems," Sol. Energy, vol. 83, no. 1, pp. 81-89, 2009, doi: 10.1016/j.solener.2008.07.008.

[10] T. Liao and J. Lin, "Optimum performance characteristics of a solar-driven Stirling heat engine system," Energy Convers. Manag., vol. 97, pp. 20-25, 2015, doi: 10.1016/j.enconman.2015.03.027.

[11] E. Gholamalizadeh and J. D. Chung, "Thermal analysis of the receiver of a standalone pilot solar dish-Stirling system," Entropy, vol. 20, no. 6, 2018, doi: 10.3390/e20060429.

[12] C.-L. Chen, C.-E. Ho, and H.-T. Yau, "Performance Analysis and Optimization of a Solar Powered Stirling Engine with Heat Transfer Considerations," Energies, vol. 5, no. 12, pp. 3573-3585, 2012, doi: 10.3390/en5093573.

[13] L. Yaqi, H. Yaling, and W. Weiwei, "Optimization of solar-powered Stirling heat engine with finite-time thermodynamics," Renew. Energy, vol. 36, no. 1, pp. 421427, 2011, doi: 10.1016/j.renene.2010.06.037.

[14] S. S. Bahari, M. Sameti, M. H. Ahmadi, and M. S. Haghgooyan, "Optimisation of a combined Stirling cycle-organic Rankine cycle using a genetic algorithm," Int. J. Ambient Energy, vol. 37, no. 4, pp. 398-402, 2016, doi: 10.1080/01430750.2014.977497.

[15] W. Reinalter et al., "Detailed performance analysis of a $10 \mathrm{~kW}$ dish/stirling system,” J. Sol. Energy Eng. Trans. ASME, vol. 130, no. 1, pp. 0110131-0110136, 2008, doi: 10.1115/1.2807191.

[16] J. Sarkar, "Novel pinch point method based exergetic optimisation of subcritical organic Rankine cycle for waste heat recovery," Int. J. Exergy, vol. 25, no. 4, pp. 
281-299, 2018, doi: 10.1504/IJEX.2018.091551.

[17] V. Siva Reddy, S. C. Kaushik, K. R. Ranjan, and S. K. Tyagi, "State-of-the-art of solar thermal power plants - A review," Renew. Sustain. Energy Rev., vol. 27, pp. 258-273, 2013, doi: 10.1016/j.rser.2013.06.037.

[18] M. Abbas, B. Boumeddane, N. Said, and A. Chikouche, "Dish Stirling technology: A 100 MW solar power plant using hydrogen for Algeria," Int. J. Hydrogen Energy, vol. 36, no. 7, pp. 4305-4314, 2011, doi: 10.1016/j.ijhydene.2010.12.114.

[19] M. A. Al-Nimr and W. A. Al-Ammari, "A novel hybrid and interactive solar system consists of Stirling engine/vacuum evaporator/thermoelectric cooler for electricity generation and water distillation," Renew. Energy, vol. 153, pp. 10531066, 2020, doi: 10.1016/j.renene.2020.02.072.

[20] A. M. A. Al-Dafaie, M. E. Dahdolan, and M. A. Al-Nimr, "Utilizing the heat rejected from a solar dish Stirling engine in potable water production," Sol. Energy, vol. 136, pp. 317-326, 2016, doi: 10.1016/j.solener.2016.07.007.

[21] X. Lai, R. Long, Z. Liu, and W. Liu, "Stirling engine powered reverse osmosis for brackish water desalination to utilize moderate temperature heat," Energy, vol. 165, pp. 916-930, 2018, doi: 10.1016/j.energy.2018.09.125.

[22] S. Ramachandran, N. Kumar, and M. V. Timmaraju, "Thermodynamic Analysis of Solar Low-Temperature Differential Stirling Engine Considering Imperfect Regeneration and Thermal Losses," J. Sol. Energy Eng., vol. 142, no. 5, Mar. 2020, doi: 10.1115/1.4046629. 